\title{
CHINESE AND AFRICAN MIGRANT ENTREPRENEURS' ARTICULATION SHAPED BY AFRICAN AGENCY
}

\author{
Dirk Kohnert \\ Institute of African Affairs \\ German Institute of Global and Area Studies \\ Hamburg, Germany
}

Giese, K, Marfaing, L (eds)(2016), Entrepreneurs Africains et Chinois. Les impacts sociaux d'une rencontre particulière. Paris: Karthala, $384 \mathrm{pp}$.

Gadzala, A (ed)(2015), Africa and China: How Africans and their governments are shaping relations with China. Lanham/Md: Rowman and Littlefield, xxix and $266 \mathrm{pp}$.

Mohan, G, Lampert, B et al (eds)(2014), Chinese Migrants and Africa's Development: New imperialists or agents of change? London: Zed books, 192 pp.

French, H (2015), China's Second Continent: How a million migrants are building a new empire in Africa. London: Penguin Random House/New York: Knopf, xi and 304 pp.

Much has been written on the relationship of China and Africa in the past decade. However, the subject of Chinese migrant entrepreneurs in Africa and their articulation with African counterparts was little explored up to the early 2010s. Apparently, this research gap has been closed, as shown by four publications in recent years: three edited volumes and one monograph, focusing on this subject. In view of early prejudices on the passive or even disapproving reception of Chinese migrants by Africans, the state of the art underlines the importance and scope of African agency vis à vis Chinese migrant entrepreneurs in Africa. This has been underlined unison in the four books under review.

The most recent volume, edited by Laurence Marfaing and Karsten Giese documents a research project on-going since six years 
at the German Institute of Global and Area Studies (GIGA-Hamburg) which combines African and Sinologist perspectives. Published in French, this can be seen as advantage and disadvantage at the same time. Considering the lack of French edited publications on this subject and the deplorable language-divide between Anglophone and Francophone Africa, the chapters (some of them translated from English) are certainly most welcomed by French speaking African readers and scholars alike. Thus, they gain the unique possibility to become familiar with the results of painstaking studies by spearheading researchers in this field of study. Some of the contributions are revised papers originally presented at a workshop at Dakar organised by the editors in January 2013 within the framework of the program Point Sud, an International Centre for Research on Local Knowledge in Bamako (Mali).

The introduction by the editors, written jointly with their research collaborator, Alena Thiel, develops the Leitmotiv of the book. It aptly captures the essence of the research findings presented in its title: "From rejecting the other to mutual involvement of both parties in the dynamics of social change" ( $p$ 7). In fact, the relations of Chinese and African petty traders and their mutual perception have changed fundamentally since the xenophobe manifestations against 'the Chinese' in several African towns as well as mutual incomprehension of both in Chinese towns (mostly in the urban districts Xiaobei and Sanyuanli of Guangzhou) where migrant African entrepreneurs arrived in the early 2000s. Many, if not most of them did not come to stay in the host country permanently, but they acted rather as sojourner, exploring the terrain in search of profitable trade, that is, Chinese imports of cheap consumer goods to Africa. Their mutual economic interest was based not so much on the general impact of political and economic globalisation but more specifically on the development of Chinese industrial production that facilitated Africans access to the desired Western products at an affordable price (pp 14-15). Thus, these entrepreneurial migrants, who incorporated globalisation from below in their very transnational economic practices, became themselves carriers of social and economic transformations in their respective host countries. The realm of these transformations covered a remarkable range, from specific accessstrategies to resources and social mobility, changing consumer behaviour, new norms and practices up to modifications of taste and ways of life ( $p$ 16).

The editors divided the volume in three parts, taking the con- 
struction of 'the other' as a pivot. First, 'the other elsewhere', opportunities of social mobility; second, encounters, stimuli for social change; and third, the production of the 'other', the 'Made in China' as social imaginary and opportunity. Beside China, the case studies concentrate on West African capitals (Accra, Dakar, Niamey, Ouagadougou) and South Africa.

Thus, Katy Lam analyses how and why three different types of Chinese citizens became entrepreneurs in Accra, taking licensed representatives or employees of Chinese state enterprises formerly working in Ghana, as well as women entrepreneurs and partners of businessmen of the local elite as an example. Their social mobility was interrelated with the articulation of social transformations in China and remained fragile despite undeniable opportunities for social and economic advancement. The same holds for Chinese women entrepreneurs in Niamey, studied by Naima Topkiran, who practice circular migration, being economically active and guarding their transnational family contacts both in their host country and at home. Their migration allowed for better living conditions and greater gender autonomy, thus initiating socio-cultural change in gender relations as well. Cultural mediation between the two worlds, Chinese and African, just as between formal and informal spheres of globalisation in their local shape is the focus of the contribution of Gordon Mathews who describes why and how certain Africans in Southern China act as intermediaries and facilitators of transnational commerce. Favoured by their affiliation to the cultural elite at home they actively searched the confidence of their Chinese counterparts and were often accepted as legitimate part of the mosaic of Chinese culture.

But social advancement is apparently not restricted to the well-todo as a case study by Kelly Si Miao Liang shows in opening the second part of the book on social encounters as stimuli of social change. Two underprivileged groups, namely African petty wholesale buyers and Chinese migrant workers living side by side in a suburb of Canton serve as an example. Their intercultural encounter opened up new realms of reasonable expectations for social promotion. Karsten Giese continues in raising the crucial question of agency concerning observed social innovations in West African trade relations. Chinese migrant entrepreneurs in Accra and Dakar appeared at the same time as employer and commercial partners of their African counterparts, for example, mobile women hawkers, belonging to the most underprivileged class in 
Ghana. They allowed the hawkers, to whom they sold parts of their goods, to resell it in the open space before their shops. Hereby the Chinese provided them with a secured space and new income earning possibilities, with due regard to the Chinese's own advantage, because they themselves profited from the low cost extension of their sales area thereby winning a competitive edge vis à vis Ghanaian competitors. Largely unwittingly, the Chinese merchants, who did not bother about the consequences of their lack of knowledge of local customs, norms and practices, thus facilitated micro innovations of social change, guided by the agency of their African counterparts. Subsequently, Ben Lampert and Giles Mohan show in their comparative case-study that local agency and class policy are central determinants of socio-economic transformation induced by the growing presence of Chinese migrant entrepreneurs, in Ghana (about 20000 in 2010) and Nigeria (150 000). Although the percentage of African actors who benefit from the Chinese presence was still limited, African agency from below profiting from this presence could develop under certain conditions to social and economic change of 'revolutionary' proportions in the host country according to the authors. Local agency as expressed in class politics plays a key role in this respect because most often the political and economic local elites profit most, sometimes to the detriment of other local interest. Apparently, the Chinese presence in Africa does not necessarily result in win-win situations for everyone. This is underlined also by Amy Niang's study of developments in Senegal, where established local operators readily admitted that the Chinese could serve as model for ambitious new and younger entrepreneurs. However, as a rule this worked only to the detriment of the prerogatives of established clientelist business networks which bitterly opposed the intruders by fomenting growing xenophobia.

The third part of the book is focused not on Chinese-African relations but on the social and economic impact of the growing presence of Chinese products, imported by Chinese and Africans alike, on African markets. Guive Khan Mohammad shows that the capture of the Burkina Faso market by motorbikes made in China resulted in almost revolutionary changes. The massive influx of motorcycles provoked not just a restructuration of the import sector from European and Japanese to cheaper Chinese bikes but also the entrance of a new generation of African small and medium enterprises and entrepreneurs (parkeurs, emballeurs, colleurs, laveurs de motos, etc), notably in the distribution 
and repair network. Moreover, the low-cost bikes created increased mobility for certain sectors of service and commerce, including adapted local consumer habits (for example brigades mobiles) and delivery networks (for example taxi-bagages). Thus, the extra mobility contributed also to improved transport connections in the countryside and in general it allowed African actors to hold their ground vis à vis the upheavals created by globalisation. No wonder then, that 'Made in China' opened new horizons and influenced the dreams of Africans of an alternative way of development from the European. Many of the respondents interviewed by Laurence Marfaing in Senegal thought it nowadays easier to earn ones living in China than in Europe to which the ways of migration are progressively closed. With it ready-made and cheap copies China 'demystified Europe' as one of her interlocutors said ( $p$ 337). Certainly, China became an alternative model. However, no model which could be copied one to one. African petty traders investigated by Marfaing in Guangzhou (Canton) for example realised that they would have to find their proper model of development, apart from that of the Chinese and the European. Thus China continued to serve as a kind of springboard for a number of young African entrepreneurs both in the acquisition of expertise and professionalism as well as of social and financial capital. It allows for a way of life other than the Western style but nevertheless a promising possibility of African participation in the process of globalisation. Finally, Alena Thiel shows in her study of the market of Chinamade products in Accra how the imaginary of 'authentic', but in reality falsified products has been utilised in the public discourse of vendors and buyers alike in their permanent negotiations about product quality and price. Whereas African transnational traders occupy their corner of the market captured from their Chinese competitors by obscuring the Chinese origin of their products in pretending to offer the fashionable original (Western) design, potential buyers evoke connotations of contraband, fake, and low quality in order to get a bargain.

All in all the volume gives an impressive, evidence based scholarly overview on the many facets of the Chinese-African encounter both in African capitals as well as in the central wholesale and retail outlets of products made in China. It incorporates painstaking case studies not just of commercial transactions and business relations but also of its repercussions for the transformation of local economic structures and social relations. Thus, it constitutes an outstanding net value added to the ongoing international discussion and opens up promising prospects 
for Africans who, due to their proper agency from below, find their place in the process of globalisation. All contributions end with a conclusion. An English summary added to each case would have enhanced international perception considerably, especially in the African countries concerned, in view of the language divide between Francophone and Anglophone Africa.

Africa and China - How Africans and their governments are shaping relations with China, edited by Aleksandra W Gadzala, a foreign policy and international development professional and frequent contributor to Oxford Analytica, follows as well the commendable aim to unearth and advance agency of everyday Africans ( $\mathrm{p} \mathrm{x}$ ). The background of her own field research in East Africa (Kenya, Uganda, Zambia, and Ethiopia) between 2006 to 2012 supplements the field experience of the editors of the first volume reviewed which is mainly focused on West Africa. Gadzala, in her introductory remarks, underlines that Africa's informal sector will continue to have the most important impact on the relationship between China and Africa because the 'unofficial China' has penetrated every conceivable walk of life. "African agents across a range of trades assert their agency within shifting political, social, and economic realities of which 'unofficial China' has become a principal driver" ( $p \times x v)$.

The volume is divided into two sections of about 100 pages each. The first, is on African state agency, including five contributions: Firstly, on the causes, consequences and perspectives of China-Africa trade by Joshua Eisenman. Secondly, on the impact of corruption as agency on the Sino-Nigerian relationship by lan Taylor. He explains that although trade and Chinese investment in resource rich Nigeria often results in massive profits, Chinas engagement remains highly volatile because of the chronic Nigerian political crisis. Any benefits the Nigerians might gain from that investment depend more on good government in Nigeria itself than on what Beijing might do for Abuja ( $p$ 40). The third contribution by Iginio Gagliardone deals with China and the shaping of African information society. Both Taylor and Gagliardone underline that the influence of China on domestic affairs is largely context related and differing between the respective host countries. In addition, the latter points out that by siding with African governments China often indifferently privileges one group of agents over the other. The fourth contribution by Lucy Corkin is on Angolan state agency and the Luanda-Beijing face-off. She shows how the ruling MPLA used sub- 
stantial Chinese loans not just for national reconstruction but also to initiate a state-building process to its own advantage which ultimately facilitated the consolidation of state power in a process of 'manufactured legitimacy' (Hodges) ( $p$ 79). The last contribution in this section by the editor herself deals with foreign-funded 'Revolutionary Democracy' in Ethiopia. She found that China's Ethiopian venture was captured by the ruling elite in Addis first and foremost in order to boost its ideological agenda and merely secondary for economic development ( $p$ 102).

The second section of the volume focuses on African agency beyond the state, that is, agency of representatives of Africa's civil society. Ben Lampert and Giles Mohan open-up the discussion with a contribution on how Ghanaian and Nigerian patrons shaped Chinese enterprises in their respective country. Their findings, based on own surveys in both countries in 2010 to 2011, reveal that Chinese business relations most often remained embedded in pre-existing African social networks of patronage dominated by African agency. African elites thereby often cemented their position which in turn provoked 'antiChinese' feelings of the underprivileged that accused the elite of lack of patriotism. Yet, network relations and agency were not uniform but incorporated multiple actors, interests and processes, closely related to accumulation and class, the state and 'cultural' dimensions ( $p$ 123). Barry Sautman continues with a chapter on racialisation as agency in Zambia-China relations. He found among others that those Africans who had tried to exploit racialisation of politics and labour relations for their own purpose often ended disillusioned because anti-Chinese moves prevented Zambians to mobilise against corrupt and oppressive foreign and domestic forces that had more agency than 'the Chinese' ( $p$ 143). Subsequently Mark Kaigwa and Yu-Shan Wu elaborate how China-Africa relations take on new meaning thanks to digital communication. The final contribution by Calestous Juma deals with the evolution of diplomatic agency in Afro-Chinese cooperation. He concludes that one of the most lasting bearings of this cooperation has been the increased confidence it has instilled in African leaders. This is not limited to Chinese affairs, but extended to Africa's relations with the West. Thus, according to Juma, it opens-up new horizons of growing African participation in global value chains made possible by globalisation (p 182).

Although the contributions differ in their assessment of origins, impact and scope of African agency within China-African relations they 
are united in underlining that African agency matters. Thereby they respond to popular misconceptions about China and Chinese entrepreneurs as agenda setters, whereas Africans are more or less helplessly overrun and outwitted. The strategically and well-selected subjects and case studies differ significantly from those included in the volume by Giese and Marfaing. Therefore, both books are perfect correlates for scholars who want to get an authoritative overview on the current state of scholarly international discussion of Chinese-African affairs. This, the more so, as an exemplary didactic structure facilitates reading of the volume edited by Gadzala. Each chapter has its own conclusion and bibliography in addition to an insightful introduction and overall bibliography at the end of the book.

Chinese Migrants and Africa's Development: New imperialists or agents of change, edited by Giles Mohan, Ben Lampert et al has been one of the first readers published focusing on Chinese migrant entrepreneurs in Sub-Saharan Africa. However, because it is about both China and Africa, mainly the second half of the volume, dedicated to Chinese socio-economic life in Africa (ch 4 to 7 ), is of interest for the purpose of this review. In detail it deals with networks and realities (ch 4), "constructing of the other: narratives of tensions and conflict" (ch 5) as well as "building bridges, conviviality, cooperation and mutual benefit in Sino-African encounter" (ch 6). The editors want to overcome limited perceptions of development as something occurring only at a national scale. They underline that development, defined as social transformation as used by Castle, comprises "a multi-layered set of actors so that by necessity we break down all-encompassing categories such as 'the Chinese', 'Africans' and, for that matter, 'development' itself" ( $p$ 151). This perception is informed by a key insight of their own research (mainly in Nigeria and Ghana, supplemented by experiences in China, Angola and Tanzania), revealing that African actors shaped much of the engagement of Chinese migrant entrepreneurs in Africa and that the often portrayed oversimplified view of "Chinese vs. Africans" does not do justice to reality. Their case studies proved on the contrary that ordinary Africans often readily appreciated the improvements which the growing Chinese presence brought about concerning their way of living and work ethics, for example in a case study in Ghana, where a respondent recognised the flat working hierarchies of Chinese shop owners employing Africans ( $p$ 133). This includes the gender dimension in Chinese migration too that is dealt with in detail in chapter four. Thus, case 
studies revealed that divorced Chinese women entrepreneurs selected Africa as new field of activity not only because of promising economic opportunities but also in order to escape social discrimination at home. The same holds for Chinese women engaged in African partnerships which were apparently more balanced than that in China. Besides, the editors aim at laying the corner stones of a theoretical framework to make sense of Chinese migration flows to Africa, including its meaning for development, based on the most notable findings from their data (pp 152-164).

Particularly, they revisit the age-old question of the specificity versus generality of the capitalist process in view of common line of argument stressing the specific Confucian values of Chinese capitalism that could not be transferred to Africans. In fact, Chinese traders focus on Africa under the pressure of local and global structural change and the incentive of potential gains in trade overseas. The race on Africa's resources is just one of several determinants of migration. Cultural incentives for entrepreneurial migrants in Africa - of Chinese and African migrant entrepreneurs alike - are not singular factors like religious orientation (for example, Confucianism, Islam and protestant ethic) but a multitude of closely interrelated socio-cultural factors and trans-national networks in which they are embedded (Kohnert 2010; Meagher 2005). Essentialist positions and similar cultural premordialism (for a biting critique see Meagher 2006) miss the point. Cultures of Innovation of migrants are not given natural or inherent driving forces. They are continuously adapted to the actual conditions at home and in the host countries. There are no robust indicators of the superiority of Chinese Cultures of Innovation vis à vis African ones. Therefore, also Mohan et al maintain that the category of social class prevailed in their study as explanatory variable as opposed to racial and ethno-cultural factors pronounced in much of the available literature. Thus, the growing intervention of Chinese entrepreneurs in Nigeria for example and resulting labour conflicts with low-skilled Nigerian labourers employed pointed to a trans-nationalisation of class relations incorporated in the Chinese presence as part of Africa's process of globalisation. Social tensions crop up notably on the sectoral level, such as trading, construction, and fishing, but also where political elites of the host country support Chinese self-interest. The editors correspondingly question the myth of the alleged 'non-interference' of the Chinese state in domestic affairs which is increasingly breaking down. 
China's Second Continent: how a million migrants are building a new empire in Africa is no scholarly analysis and does not pretend to be. It is mostly based on detailed anecdotal evidence derived from close personal encounters with Chinese migrant entrepreneurs all over SubSaharan Africa: Ghana, Guinea, Liberia, Mali, Mozambique, Namibia, Zambia, Senegal, Sierra Leone, and Zambia. Nevertheless it is a beneficial correlate to the aforementioned scholarly publications because French opens up authentic vistas of personal relations and empathic attitudes that are essential for the real understanding of the subject. The book contains valuable insights even for Africanists and scholarly experts. Howard W French, the former bureau chief of the New York Times for both West Africa and China, fluent in Chinese and apparently especially gifted to pick people up where they stand, reveals a close understanding of the special cultural and socio-economic conditions of Chinese migrants in Africa and their interrelations with African counterparts. The book comprises three chapters, each with detailed descriptions of personal encounters with Chinese migrant entrepreneurs in different African countries, as well as an epilogue on the comparative evaluation of Chinese, Western, and Japanese 'imperialism' in Africa (pp 259-264). Most of the Chinese migrants French meets did not receive any assistance from the Chinese government, they relied mainly on their own resources and family-based chain migration. Few of them consider Africa as a promised land. Most often they selected the host country intentionally because of promising profit margins as well as personal and political freedom available in the host- in contrast to their home country. However, as a rule they did not intend to stay indefinitely, at least not in the beginning. Either they wanted to return to China or the sojourners considered Africa as a springboard for moving on to Western countries. With his accounts French tries to unmask a range of prejudices of the 'ugly Chinese' not interested in African culture nor in the fair treatment of his African employees. Certainly, such personalities exist, yet they are no exemption but to be found in Lebanese, Indian or European trading diasporas in Africa too. Apart from politically instrumentalised xenophobia, most Africans encountered by French show quite realistic attitudes towards Chinese migrant entrepreneurs and their intentions. Moreover, they welcome the cheap Chinese imports as a valuable alternative to Western products. Furthermore, they recognise the Chinese development model as promising alternative to the Western model, yet "if Africa really wants to follow China's lead, it will 
need its own Shenzhen, and it will have to build it by itself"2) (Smith 2015: 18).

\section{Endnotes}

1. This all the more, as some scholarly reviews of the book are already available (Jacob 2016; Marfaing 2015, Zafar 2015; Lin 2014).

2. Shenzen, a small town located in the vicinity of Hong Kong, China's first Special Economic Zone in 1980, became one of the fastest growing cities worldwide. With over ten million inhabitants it is now a major commercial and financial center in southern China, in short a symbol of the newly acquired development potential of China.

\section{Bibliography}

Jacob, J T (2016). "Chinese migrants and Africa's development: New imperialists or agents of change? (Book review)", Africa Review, Vol 8, No 1, pp 71-72.

Kohnert, $\mathrm{D}$ (2010). Are Chinese in Africa more innovative than Africans? Comparing Cultures of Innovation of Chinese and Nigerian entrepreneurial migrants, Hamburg: GIGA-WP, No 140.

Lin, E (2014). "Chinese Migrants and Africa's Development: New Imperialists or Agents of Change? (Book review)", Journal of Development Studies, Vol 50, No 12, pp 1736-1737.

Marfaing, L (2015). "Book reviews: (1) Alden and Chichava (eds) (2014), China and Mozambique: From Comrades to Capitalists. (2) Mohan et al (2014): Chinese Migrants and Africa's Development", Africa Spectrum, Vol 50, No 1, pp 95-98.

Meagher, K (2006). "Cultural primordialism and the post-structuralist imaginaire: Plus ça change ...", Africa, Vol 76, No 4, pp 590-597.

Meagher, K (2005). "Social capital or analytical liability? Social networks and African informal economies", Global Networks, Vol 5, No 3, pp 217-238.

Smith, S W (2015). "China's Second Continent: How a Million Migrants Are Building a New Empire in Africa (Book review)", London Review of Books, Vol 37, No 6, pp 15-18.

Zafar, A (2015). "Chinese migrants and Africa's development: new imperialists or agents of change? (Book review)", Labor History, Vol 56, No 3, pp 376-378. 